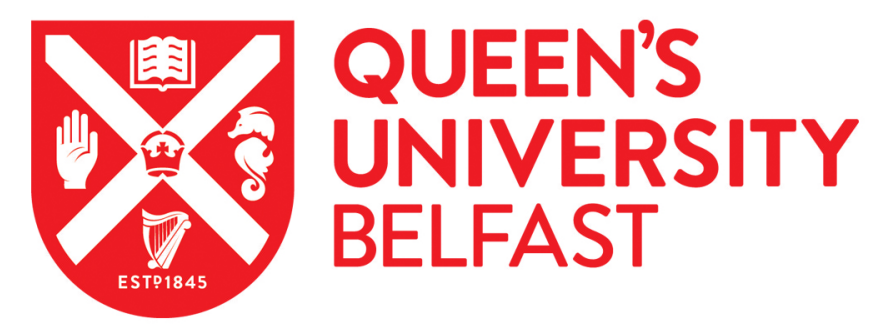

\title{
Characterization of High-Performance Organic Dyes for Dye- Sensitized Solar Cell: A DFT/TDDFT Study
}

Lambert, C., Mao, Y., Zheng, Y-Z., Tao, X., Hu, P., \& Huang, M. (2016). Characterization of High-Performance Organic Dyes for Dye-Sensitized Solar Cell: A DFT/TDDFT Study. CANADIAN JOURNAL OF CHEMISTRYREVUE CANADIENNE DE CHIMIE. https://doi.org/10.1139/cjc-2016-0294

Published in:

CANADIAN JOURNAL OF CHEMISTRY-REVUE CANADIENNE DE CHIMIE

Document Version:

Peer reviewed version

Queen's University Belfast - Research Portal:

Link to publication record in Queen's University Belfast Research Portal

Publisher rights

(C) Copyright 2014 - Canadian Science Publishing

\section{General rights}

Copyright for the publications made accessible via the Queen's University Belfast Research Portal is retained by the author(s) and / or other copyright owners and it is a condition of accessing these publications that users recognise and abide by the legal requirements associated with these rights.

Take down policy

The Research Portal is Queen's institutional repository that provides access to Queen's research output. Every effort has been made to ensure that content in the Research Portal does not infringe any person's rights, or applicable UK laws. If you discover content in the Research Portal that you believe breaches copyright or violates any law, please contact openaccess@qub.ac.uk. 


\section{Characterization of High-Performance Organic Dyes for Dye-Sensitized Solar Cell: A DFT/TDDFT Study}

Christopher Lambert ${ }^{1 \#}$, Yu Mao ${ }^{1 \#}$, Yan-Zhen Zheng², Xia Tao², P. Hu${ }^{1}$, Meilan Huang ${ }^{1 *}$

1. School of Chemistry and Chemical Engineering, Queen's University Belfast, David Keir Building, Stranmillis Road, Belfast, Northern Ireland, United Kingdom

2. State Key Laboratory of Organic-Inorganic Composites, Beijing University of Chemical Technology, Beijing 100029, China

In honour of Prof Arvi Rauk and Prof Russell Boyd

\# These two authors contribute equally to this paper

* Corresponding author: Meilan Huang

E-mail: m.huang@qub.ac.uk

Tel: $+44(0) 28-9097-4698$

Fax: +44(0)28-9097-6524 


\begin{abstract}
Dye-sensitized solar cell (DSSC) is currently a promising technology that makes solar energy efficient and cost-effective to harness. In DSSC, metal free dyes, such indoline-containing D149 and D205, are proved to be potential alternatives for traditional metal organic dyes. In this work, a DFT/TDDFT characterization for D149 and D205 were carried out using different functionals, including B3LYP, MPW1K, CAM-B3LYP and PBE0. Three different conformers for D149 and four different conformers for D205 were identified and calculated in vacuum. The performance of different functionals on calculating the maximum absorbance of the dyes in vacuum and five common solvents (acetonitrile, chloroform, ethanol, methanol, and THF) were examined and compared to determine the suitable computational setting for predicting properties of these two dyes. Furthermore, deprotonated D149 and D205 in solvents were also considered, and the highest occupied molecular orbital (HOMO) and lowest unoccupied molecular orbital (LUMO) were calculated, which elucidates the substitution effect on the rhodanine ring of D149 and D205 dyes on their efficiency. Finally, D149 and D205 molecules were confirmed to be firmly anchored on ZnO surface by periodic DFT calculations. These results would shed light on the design of new highly efficiency metal-free dyes.
\end{abstract}

\title{
Key words
}

Dye molecule, metal-free, DSSC, DFT, TDDFT, excitation 


\section{Introduction}

The sun is projected to give out 10,000 times the global energy demand and this abundance as well as environmentally friendliness make it the ideal energy source and promising alternative for fossil fuels. All that remains is to make the collection and conversion of the solar radiation efficient and cost-effective to harness. ${ }^{1}$ Many different variants of solar cells have been reported and are in use currently. Among that, the dye sensitized solar cell (DSSC) from the thin film solar cell family has attracted much attention in the research community for its development and efficiency improvement. ${ }^{2-5}$ The modern day version of this technology was originally invented by Grätzel et al, who achieved an energy conversion yield of $7.1 \%{ }^{6}$ and further elevated its efficiency to $13 \% .{ }^{7}$ Perovskite solar cell stemming from DSSC has reached the efficiency of 22\% rapidly since its inception by replacing the liquid electrolyte in DSSC with solid hole conductor. ${ }^{8}$

A DSSC is typically employed via light being absorbed by a monolayer of dye molecules which are anchored to a mesoporous nanocrystalline metal oxide semiconductor, such as $\mathrm{TiO}_{2}$, which then proceeds via photoexcitation to undergo electron injection into the conduction band of the oxide followed by trap-limited diffusion. Upon photoexcitation and subsequent injection of sensitizer molecule electrons from their excited states into the conduction band of the semiconductor, the electrons migrate through the external load which in turn enables electricity generation. The dye is then regenerated, returned to its neutral state, by an oxidation-reduction pair such as $\mathrm{I}^{-} / \mathrm{I}_{3}{ }^{-}$, with which the porous oxide layer is permeated. ${ }^{8,9}$ Traditionally, most DSSC dyes include metal centre like ruthenium, e.g. the N3 and N719 dyes (Fig. $1 \mathrm{a}$ and b). With the demand for these source-limited noble metals going up in other sectors of industry it is desirable to find cheaper, more efficient and more environmentally friendly 
metal-free organic dyes. ${ }^{10,11}$ Most of organic dyes involve a 'push-pull' architecture and have been shown to be very effective as efficient sensitizers. ${ }^{12}$ They typically include a D- $\pi$-A structure; the donor group (D) is the electron rich species which donates through a $\pi$ bridge spacer to an electron accepting group (A). Indeed, it has been shown that electronic delocalization along the $\pi$-bridge ensures overlap between the ground and excited states, which is crucial for good molar extinction coefficients. ${ }^{11}$ Arylamine derivatives are well-known organic dyes. ${ }^{13} \mathrm{~A}$ variety of arylmaine donor structures have been reported such as coumarin, ${ }^{14}$ binary $\pi$ conjugated triphenylamines, ${ }^{15}$ phenyl-conjugated oligoeenes, ${ }^{16}$ merocyanines ${ }^{17}$ and hemicyanines. ${ }^{18}$

Among organic dyes, indoline dyes have showed great promise in the forms of D149 and more recently D205 (Figure 1 c and d). The D149 dye has been of keen interest over the past years. It has been found to exhibit remarkable performance in DSSC systems in conjunction with ionicliquid or AcCN based electrolytes, exhibiting conversion efficiencies of 9.03 and 6.67\%, respectively. ${ }^{19}$ Furthermore, a derivative molecule denoted D205 was designed via introduction of an n-octyl group substitute onto the rhodanine ring of D149. This molecule has shown a promising efficiency of $9.52 \% .{ }^{20}$ Although it is not as efficient as the ruthenium-containing dye N719, which has currently shown an efficiency of $10.29 \%,{ }^{21}$ it should also be noted that the long alkyl chain in D205 prevents recapture of photoinjected electrons by ions in the electrolyte. This accounts for the higher $\mathrm{V}_{\text {oc }}$ value associated with D205 compared with N719. ${ }^{22}$

Theoretical studies have been conducted along with experimental work in the development of DSSCs, in order to understand the electronic properties such as structure, electronic and absorption properties of the dyes as well as adsorption of the dyes on surfaces. ${ }^{23}$ Despite the promising electron-donating ability of indoline, the theoretical insights into indoline-containing 
dyes such as D149 and D205, however, are far from enough. Currently, no consensus had been achieved on the proper computational setting on calculating these two dyes. Since the characterization of D149 and D205 involves the calculations of excited states, time-dependent density functional theory (TDDFT) has to be used. In addition, it is imperative to decide which of the several commonly used functionals, B3LYP, MPW1K, CAM-B3LYP and PBE0, would be most suitable for predicting the properties of organic dyes like D149 and D205. Zhang et al. tested the maximum absorbance of one conformers of D149 and D205 in vacuum and tetrahydrofuran (THF); ${ }^{24}$ however, a more detailed and comprehensive study with different dye conformers and solvents are required. In this work, three possible conformers of D149 and four conformers of D205 were identified and investigated using four different functionals with DFT/TDDFT calculations, followed by calculations of their maximum absorbance in both vacuum and five different solvents (acetonitrile, chloroform, ethanol, methanol, and THF). The performance of different functionals is investigated for the neutral forms of D149, D205 as well as their deprotonated states. Moreover, the viability of these two dyes was confirmed by their HOMO and LUMO energies. Finally, periodic DFT calculations were carried out for simplified model of D149 and D205 on the ZnO (1010) surface, which confirms that the dye molecules can be firmly anchored by the surface. Our work theoretically characterizes D149 and D205 dyes and provides a general guidance on the performance and choice of functionals in both vacuum and different solvents, which would shed light on the design of novel highly efficient metal-free dyes in the field of the dye-sensitized solar cell.

\section{Computational Methods}

The computations of geometries, electronic structures and relevant energies of dyes in vacuum and solvents were performed using DFT with the Gaussian 09 package. ${ }^{25}$ The polarized split- 
valence 6-31G* basis sets were used throughout the study unless otherwise specified. Several density (DFT) functionals, including B3LYP, ${ }^{26,27} \mathrm{MPW}^{28}{ }^{28}$, CAM-B3LYP ${ }^{29}$ and PBE0 ${ }^{30}$, were employed for comparison, which will help dictate the computational expense and accuracy of results. The default convergence criteria for maximum step size and RMS force was used in geometry optimizations, and tight convergence was employed in SCF. The most important conformers of the dyes was considered by rotating around the crucial bonds related to the electron transfer, i.e. the C-N bond between the triphenyl group and the five-membered $\mathrm{N}$ hetercycle of the electron donor indoline, and the $\mathrm{C}-\mathrm{C}$ bond between the phenyl ring of the indoline and the ethenyl group attached to the electron acceptor rhodanine. Only the lowestenergy conformation for each of these rotations was reported (con1-con3). For D205, we also considered the extended conformation of the n-octyl chain in addition to the wiggled ones (con4).

The electronic absorption spectra calculated based on allowed excitations and oscillator strengths were carried out by TDDFT method ${ }^{31}$ in gas phase and solvent. Time-dependant DFT (TDDFT) method, although associated with great complexity and computational expense, can be employed to calculate interesting properties related to excited states. It allows for accurate derivation of HOMO and LUMO energy values for excited states, as well as recording the absorbance of a molecule. The Polarizable Continuum Model (PCM) ${ }^{32}$ using the CPCM polarizable conductor calculation $^{33}$ was adopted for considering the solvent effects. The average density of integration points on the surface was set to the default value of $5.0 \AA^{-2}$. The solute was placed in a sphere with the UFF radii scaled by a factor of 1.1. In solvation calculations, single point energy calculations were performed based on the optimized geometries in vacuum using respective calculation methods. 
The maximum absorbance wavelengths were determined from the maximum absorbance in UVVIS spectrums that generated by Gaussview 5.0. ${ }^{34}$ (Supporting information Fig. S1-S10).

The two dyes were then modelled on the $\mathrm{ZnO}(10 \overline{10})$ surface and spin-polarized calculations were carried out using the Vienna ab initio simulation package (VASP) ${ }^{35,36}$ with $\mathrm{PBE}^{37}$ functional. The project-augmented wave (PAW) method was used to represent the core-valence interaction. ${ }^{38,39}$ In total energy calculations, a cut-off energy of $450 \mathrm{eV}$ was set for plane wave basis sets to expand the valence electronic states. All atoms were optimized using the BroydenFletcher-Goldfarb-Shanno minimization scheme until the force of each atom was lower than $0.05 \mathrm{eV} / \AA$. In the modelling of $\mathrm{ZnO}(1010)$ surface, a (2×3) supercell was used with a vacuum of $12 \AA$ to avoid interactions between neighbouring images. The surface was represented by four atomic layers with the bottom two layers fixed, and a $2 \times 2 \times 1 \mathrm{k}$-point was used to sample in the Brillouin zone of the surface. The adsorption energy $\left(E_{a d}\right)$ of dyes is defined as:

$$
E_{a d}=E(\text { dye in the solvent/surface })-E(\text { dye in the solvent })-E(\text { surface })
$$

where a more negative $E_{a d}$ value corresponds to a stronger adsorption.

\section{Results and Discussions}

\section{D149 and D205 dyes in vacuum}

Three different conformers of D149 and four different conformers of D205 were considered in the calculations, namely D149con1-3 (Fig. 2) and D205con1-4 (Fig. 3); starting from con1, a new conformer con2 was generated by rotating the C-N bond between the indoline ring and benzene ring connected to it; con3 was also derived from con 1 by rotating the C-C bond between the indoline phenyl ring and rhodanine ethenyl group. For D205, a fourth conformer was derived 
from con3 by rotating the C-C singe bond in the octyl chain. It should be noted that the conformers previously investigated for D149 and D205 correspond to our D149con3 and D205con4, and therefore they are used as comparison in this work.

Geometry optimization of all different conformations of D149 and D205 and the relative energies of the conformers were calculated (Table 1). It shows that the energy of con2 is slightly higher than con1 whereas the energy difference between con3 and con1 is negligible for both dye molecules. The energy of D205con4 is almost same as that of D205con3, indicating the rotation within the octyl chain only has marginal effect on the dye stability. Thus D205con3 and D205con4 are interchangeable without overcoming energy barrier. Because D149con3 and D205con4 have been reported in the previous research, ${ }^{24}$ we will focus on D149con1, D149con3, D205con1 and D205 con4 hereafter.

Maximum absorbance wavelengths of D149 and D205 in vacuum were calculated (Table 1). For D149, the values of excitation energy and absorbance of con1 and con3 match well with the results of Zhang et al, ${ }^{24}$ whereas the result for con2 deviates to some extent. This is because con1 and con3 are the most stable conformations that D149 can adopt, as indicated by their close energies. Also it is noticeable that the difference in the conformations of D149con1 and D149con3 do not seem to have a large impact on the excitation energy of the molecule. In both conformers, LUMO is located around the anchoring carboxylate group and HOMO is delocalized toward opposite end of the dye, which makes electron injection facile. Interestingly, despite of the different spacial arrangement of the electron donor indoline in relation to the electron acceptor rhodanine, both conformers display similar orbital occupancy indicating the delocalization around the D- $\pi$-A moiety is not affected by rotating around the rhodanine (Fig. 4). 
D205con1 and D205 con4 also have similar absorbance and excitation energies, comparable to the literature value. This again indicates that the rotation of the rhodanine ring has little effect on electron excitation. D205con2, similar to D149con2, deviates from the rest conformers significantly and indicates the rotation around the indoline group has a greater effect on maximum absorbance wavelengths and excitation energies (Fig. 3). It should be noted that in the case of D205con3, the octyl group is more perpendicular to the D- $\pi$-A moiety of the molecule which would make dye adsorption onto a semiconductor more difficult.

In addition to the default functional B3LYP, two additional functional CAM-B3LYP and MPW1K were also applied for the various conformers of D149 and D205. From the results in Table 1, both of their values are well below the results from B3LYP, which indicates that neither of CAM-B3LYP and MPW1K may be suitable for calculating D149 and D205. It is known that the MPW1K method deteriorates as the degree of charge transfer increases which may explain why the results obtained from this method are off the mark. ${ }^{40}$

\section{D149 and D205 dyes in solvents}

After examining the absorbance by TDDFT calculations in vacuum for the possible conformers of D149 and D205, the two low-energy conformations were chosen for further analysis in solvents using the CPCM solvation model. The results of D149con3 and D205con4 are listed in Table 2 and 3. The solvent analyses were also conducted for D149con1 and D205con1, which show a similar trend and listed in the supporting information (Table S1 and Table S2). CPCM model is a polarization continuum model which treats the solvent as a polarizable continuum. It corrects the ground-state molecular orbitals and energies of solutes in solvents and has been shown to be effective in modelling solvent effects. ${ }^{32,33}$ 
The results using four different functionals (B3LYP, MPW1K, CAM-B3LYP and PBE0) are listed in Table 2. Using B3LYP functional, our computed absorbance value in ethanol as well as in chloroform is in good agreement with the experimental results (566 vs. Exp. 564 in ethanol, 557 vs. Exp. 550 in chloroform). However, the calculated values in acetonitrile (566), methanol (566) and THF (561) using the B3LYP hybrid functional are all higher than the experimental values (Exp. 526, 527 and 526, respectively). The results show that in these solvents the absorption bands shift to higher wavelengths, which is a result of solvatochromism. The results of both MPW1K and CAM-B3LYP deviate considerably from the experimental values. This is not surprising as these functionals were suggested to seriously underestimate the absorbance for large indoline dyes such as D149. ${ }^{41}$ Moreover, the PBE0 functional, which involves the combination of the PBE exchange energy and Hatree-Fock in a 3 to 1 ratio, ${ }^{30}$ were employed for calculating the maximum absorbance for dyes. On the contrary to B3LYP, PBE0 give rise to quite good predictions for acetonitrile (536), methanol (535) and THF (532) solvent, corresponding well with the experimental values of 526, 527 and 526, respectively. However, PBE0 overestimated those for chloroform and ethanol (529 and 539 vs. Exp 550 and 564, respectively). These results indicate that both B3LYP and PBE0 functionals are within a reasonable margin of error from one another and either could be complementary to each other when they are employed to predict the absorbance in various solvents. It is worth mentioning that the absorbance in the THF solvent was calculated using CAM-B3LYP and PBE0 functionals with $6-31+G(d, p)$ basis set in previous study. ${ }^{24}$ Our results in THF using same functionals with 6-31G(d) basis set are in line with their calculated absorbance data. This indicates that little difference is introduced when polarization and diffuse effect were considered and 6-31G(d) basis set may be sufficient to predict the absorbance in various solvents. 
The results of D205 in various solvents are displayed in Table 3. The accuracy in predicting the maximum absorbance using different functionals shows similar trend as we observed for D149. It is obvious that MPW1K and CAM-B3LYP still underestimate the maximum absorbance values compared with the experimental values as well as those predicted by B3LYP, PBE0 functionals. B3LYP shows a reasonable accuracy in the prediction in chloroform, whereas PBE0 performs better in THF. Similar to D149, larger basis set, 6-31+G(d, p) combined with CAMB3LYP and PBE0 give rise to similar results as those calculated using the 6-31G* basis set.

\section{Deprotonated D149 and D205 dyes}

D149 and D205 could be deprotonated in a DSSC in order to interact with the catalytic surface. Therefore, an analysis using the 6-31G(d) basis set, B3LYP hybrid functional, and the CPCM solvation model was carried out on the representative low-energy conformers D149con3 and D205con4, respectively. Comparable data have previously been calculated by Fakis et al. ${ }^{42}$ The structure of deprotonated D149con3 and D205con4 are shown in Fig. 5, and their corresponding maximum absorption are listed in Table 4. It can be seen that the absorbance values of deprotonated D149con3 and D205con4 are comparable with the experimental results, although it can be noted that blue shifts of the absorbance maxima are observed for the deprotonated dye molecules. This is understandable as the deprotonation would give way to a negative charge on the molecule making it more polar. Interestingly, the values of D149con3 in each solvent are very close to those of D205con4 in its equivalent solvent. It can also be noted that for both D149con3 and D205con4, their absorbance values calculated by B3LYP functional in THF are very comparable to the experimental data. Thus, B3LYP appears to be sufficient for predicting the absorbance in THF. Generally, B3LYP results show better agreements on chloroform, ethanol and THF solvent, while PBE0 functional performs better on acetonitrile and methanol. 


\section{Viability of the Dye Molecules}

In DSSCs there are several key factors which influence their effectiveness and efficiency upon irradiation. One of the factors is the ability of electron injection of photoexcited electrons into the metal oxide conduction band. Another is the electron coupling between the lowest unoccupied molecular orbital (LUMO) of the dye and the conduction band of the metal oxide. The LUMO of the dye must be higher (more negative) than the conduction band edge of the metal oxide and it should be located at the acceptor part of the dye to provide efficient electron injection. ${ }^{43,44}$ The HOMO energy of the dye should be lower (more positive) in comparison to the redox potential of electrolyte for efficient dye regeneration. Therefore, it is worth exploring the ability of the molecules to be used as dyes, in terms of HOMO and LUMO levels in relation to the conduction band of metal oxides and electrolyte redox potential.

Specifically, in order for these dye molecules to be effective, the HOMO energy levels of D149 and D205 must be above the valence band but below the conduction band of the semiconductor. Also, the LUMO must lie above the conduction band. These conditions must be met in order to facilitate electron injection from the dye to the metal oxide. Two common DSSC materials, $\mathrm{ZnO}$ and $\mathrm{TiO}_{2}$, have valence band energies of -7.39 and $-7.41 \mathrm{eV}$ as well as conduction band energies of -4.19 and $-4.21 \mathrm{eV}$, respectively. ${ }^{345}$ The HOMO and LUMO orbitals of D149con3 and D205con4 were calculated and shown in Fig. 4. We also calculated the ionization potentials (IP) of D149 and D205, based on the respective energy difference between the neutral dye and the oxidized dye, $\mathrm{D}-\mathrm{D}^{+}$. The energies of the neutral and oxidized dyes were obtained from fully optimized geometries using B3LYP/6-31G(d) method (Table 5). The ionization potentials were estimated with respect to normal hydrogen electrode $\left(\varepsilon_{\mathrm{NHE}}=-4.43 \mathrm{~V}\right)$. A schematic energy diagram is shown in Scheme 1exhibiting the relative positions of HOMO and LUMO, in relation 
to the conduction band edge of the semiconductor $\mathrm{ZnO}$ or $\mathrm{TiO}_{2}$. As can be seen in Scheme 1, the LUMO of both dyes are higher than the conduction edge of $\mathrm{ZnO}$ or $\mathrm{TiO}_{2}$, and LUMO is lower than the electrolyte redox potential $(\sim 0.4 \mathrm{~V})$. This is in line with their ability to function as effective sensitizers for a DSSC. The IP of D205 (1.56 V) is closer to the electrolyte redox potential than D149 (1.65 V), as a result electron is easier to transfer from electrolyte to HOMO, facilitating dye regeneration. We can conclude the IP order of the two dyes estimated by the current DFT calculations is in accordance with the trend in their conversion efficiency. Interestingly, rotation around the rhodanine ring has little impact on the excitation energies and the absorbance maxima of the dyes. As mentioned previously, this is related to the features of the HOMO and LUMO, with LUMO being located around the rhodanine acceptor and HOMO populated around the opposite end. Whereby it has been noted that such orbital configuration is not affected by rotating around the rhodanine ring and decreases the possibility for charge recombination by "hole trapping”, ${ }^{41}$

\section{Periodic DFT calculation of dyes on metal oxides}

A DSSC device is typically employed via light being absorbed by a monolayer of dye molecules which are anchored to a metal oxide semiconductor of mesoporous nanocrystalline, such as $\mathrm{TiO}_{2}$ and $\mathrm{ZnO}$, which then proceeds via photoexcitation to undergo electron injection into the conduction band of the oxide by trap-limited diffusion. Therefore, together with the properties of the dyes in vacuum and different solvents, it is also of great interest to explore their behaviours on the surfaces of metal oxides. Recently $\mathrm{ZnO}$, which has similar band gap as $\mathrm{TiO}_{2}$ and therefore similar physical chemical properties, has become an emerging alternative semiconductor material to traditional $\mathrm{TiO}_{2}$ because of its outstanding properties in high electron mobility, facile fabrication and easy adjustability of size and morphology. ${ }^{46,47}$ 
Here, we investigated the interaction between the dyes and $\mathrm{ZnO}(10 \overline{10})$, which is common surface for ZnO modelling. ${ }^{-48-50}$

Since the original D149 and D205 molecules are too large to be treated by periodic DFT calculations on the surface, a simplified model was used that contains the atoms that interact directly with the surface, i.e. the anchoring carboxylic acid group and the attached rhodanine ring(Fig. 6). This is reasonable since the carboxylic acid group is usually regarded as strong adsorption group on metal oxides surfaces. In order to consider the solvent effect, we employed the VASPsol model, an implicit solvation model that describes the effect of electrostatics, cavitation, and dispersion on the interaction between a solute and solvent. ${ }^{51}$ The model, now implemented into the plane-wave DFT code VASP, ${ }^{52}$ has been successfully applied in metal and semiconductor surfaces with standard ultrasoft pseudopotential and projector-augmented wave potential libraries. ${ }^{53}$ The adsorption energy of the dye model on $\mathrm{ZnO}$ surface was calculated in acetonitrile, a common solvent used in DSSC. ${ }^{54}$

The dye model was positioned on the surface with its carboxylic acid group attached to the zinc atom of the $\mathrm{ZnO}$ surface. Two stable adsorption structures of the dye model are identified (Fig. 6) with adsorption energy of -1.48 and $-2.06 \mathrm{eV}$, respectively. The figure clearly indicates that the dye model indeed interacts with the surface with good adsorption strength. In both adsorption structures, the ketone group binds with a surface Zn atom, while the hydroxyl remains free (Fig. 6a) or interacts with a surface $\mathrm{O}$ atom (Fig. 6b). When the hydroxyl interacts with a surface $O$, the $\mathrm{OH}$ bond is significantly elongated (Fig. 6b), which can be regarded as dissociative adsorption. As a result, its adsorption energy increases from -1.48 to $-2.06 \mathrm{eV}$. Our periodic DFT calculations confirm that the dyes (D149 and D205) can be anchored by the surface of the metal oxide. 


\section{Conclusions}

In this work, a DFT/TDDFT investigation towards two indoline-containing DSSC dyes, D149 and D205 was carried out with the consideration of different conformers of D149 and D205. Several different functionals, including B3LYP, MPW1K, CAM-B3LYP and PBE0 were used when calculating the maximum absorbance of the dyes in vacuum and five common solvents (acetonitrile, chloroform, ethanol, methanol, and THF). Following results were obtained:

1. The most important conformers of the dyes was considered by rotating around the crucial bonds related to the electron transfer. Three possible conformers of D149 and four possible conformers of D205 were identified using B3LYP method and 6-31G* basis set. Both dye molecules can exist in the two low-energy conformations, con1 and con3. D205 can exit in a fourth low-energy conformation where the n-octyl chain attached on the rhodanine ring extends away from the D- $\pi$-A system. The most stable conformation of the dye molecules can be used to guide the design of new metal-free dyes to have admirable electronic and absorbance properties, i.e. by mimicking the spatial arrangement of electron donor indoline in relation to electron acceptor rhodanine, as shown in the two low-energy conformations con1 and con3 in the congeneric dyes; highefficient dye may be achieved by tweaking the substitution group on the rhodanine into the conformations adopted by D205con3 and D205con4.

2. The electron donor feature of the indoline group and electron acceptor feature of the rhodanine group by frontier HOMO and LUMO analysis accounts for the experimental observations that the akyl substitution on the rhodanine ring has little impact on the excitation energies and absorbance spectrum. 
3. The absorbance data predicted by B3LYP method and 6-31G* basis set in vacuum are in good agreement with the experimentally obtained maximum absorbance, indicating that B3LYP/6-31G* is adequate for calculating absorbance properties of the indoline dyes. MPW1K and CAM-B3LYP, on the other hand, seriously underestimated the maximum absorbance of the indoline dyes in vacuum.

4. In solvents, MPW1K and CAM-B3LYP do not perform as well as B3LYP and PBE0 methods. B3LYP shows a good prediction for chloroform and ethanol, while PBE0 gives better results for acetonitrile, methanol and THF. Thus PBE0 and B3LYP methods could be complementary on calculating the properties of indoline dyes in polar solvents.

5. The deprotonated D149 and D205 are also considered in solvents and show a similar trend compared with the neutral dyes.

6. Periodic DFT calculations of the dyes on a $\mathrm{ZnO}$ surface disclose two stable structures at adsorption and confirm that D149 and D205 molecules can be firmly anchored by the surface.

\section{Acknowledgements}

The authors are grateful for the computing resources from QUB high performance computing Centre and acknowledge the helpful discussion with Dr Ziyun Wang. 
Figures and Tables

\section{Figures}

(a)<smiles></smiles>

N3

(c)

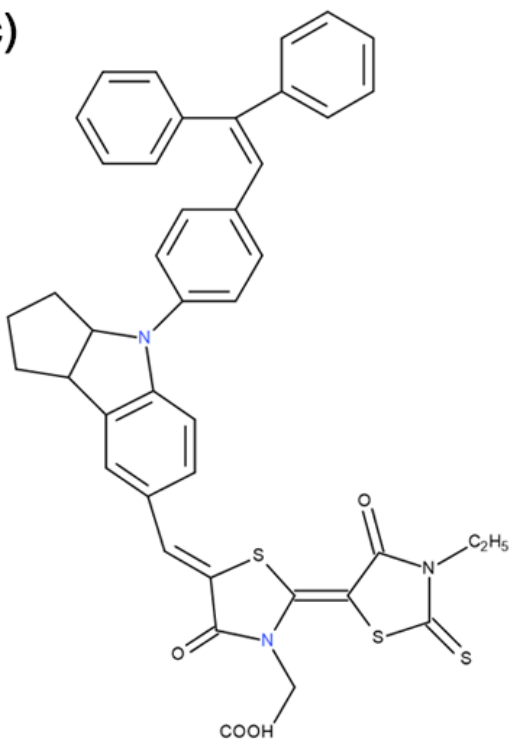

D149

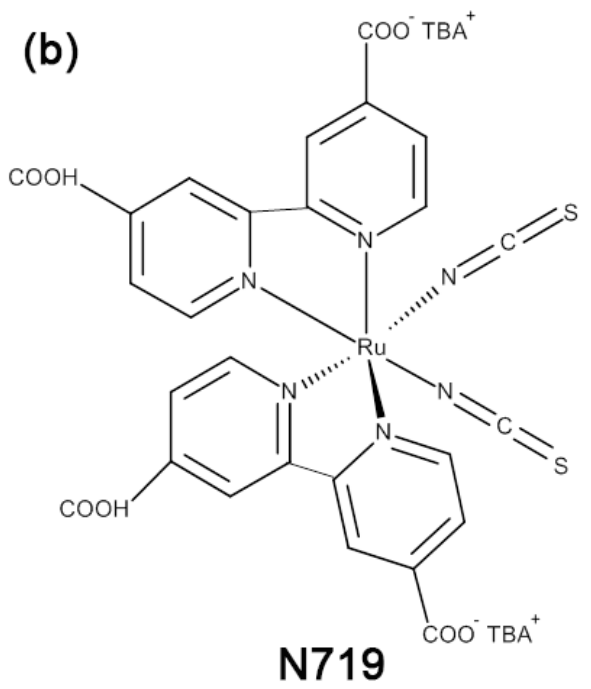

(d)

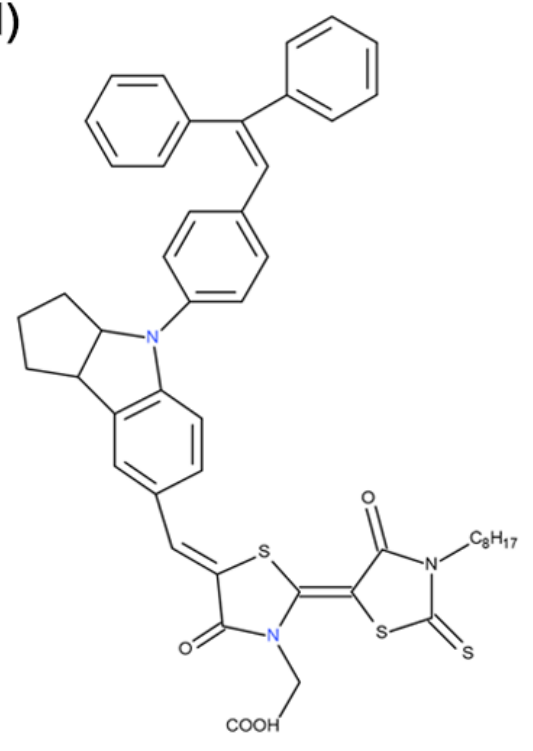

D205

Figure 1. Structures of the organometallic dyes (a, b) and metal-free organic dyes (c, d). 

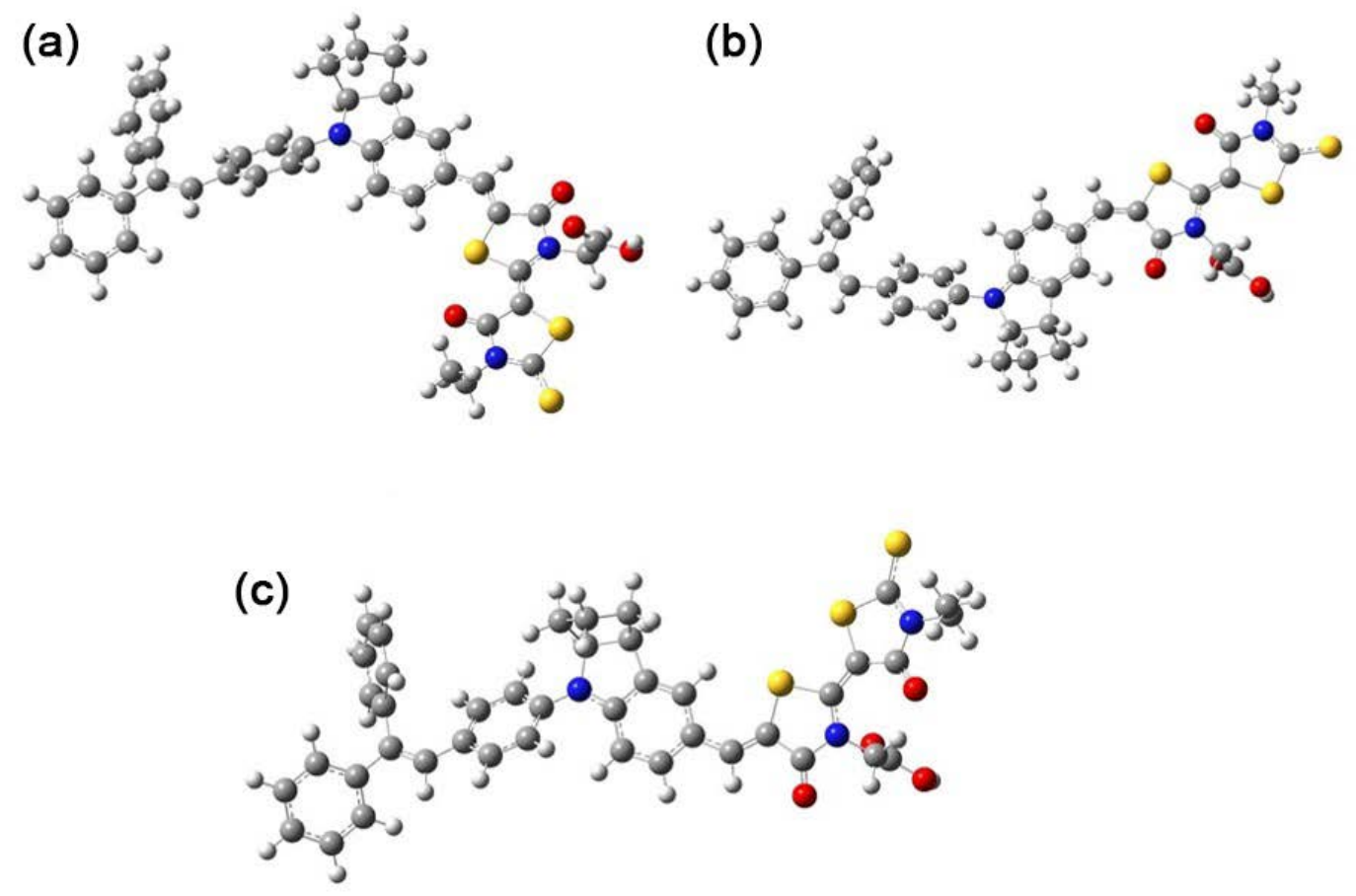

Figure 2. 3D geometries of (a) D149con1 (b) D149con2 (c) D149con3. The grey, white, blue, yellow and red balls represent $\mathrm{C}, \mathrm{H}, \mathrm{N}, \mathrm{S}$ and $\mathrm{O}$, respectively. 

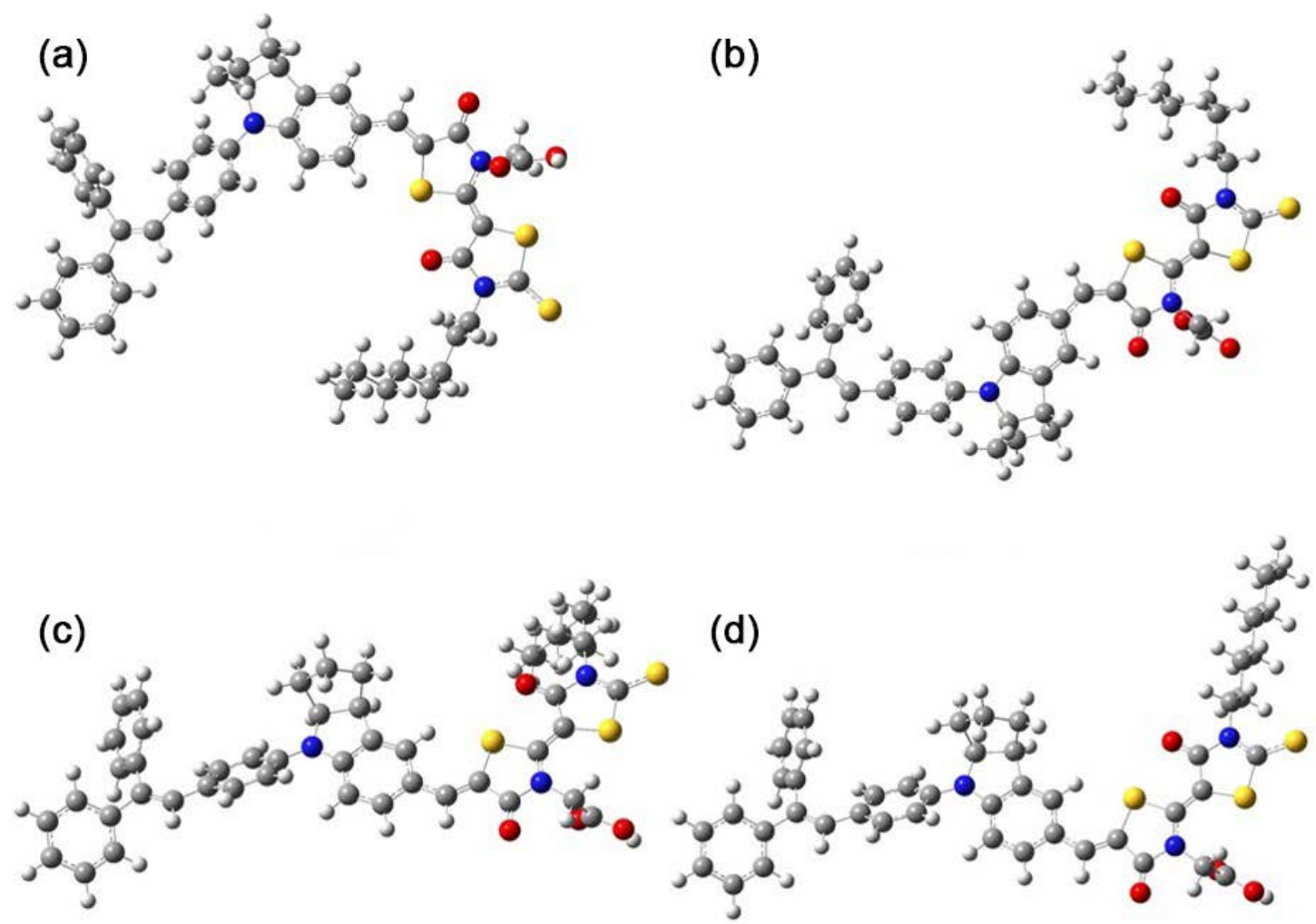

Figure 3. 3D geometries of (a) D205con1, (b) D205con2, (c) D205con3 and (d) D205con4. The grey, white, blue, yellow and red balls represent C, H, N, S and O, respectively. 
(a)

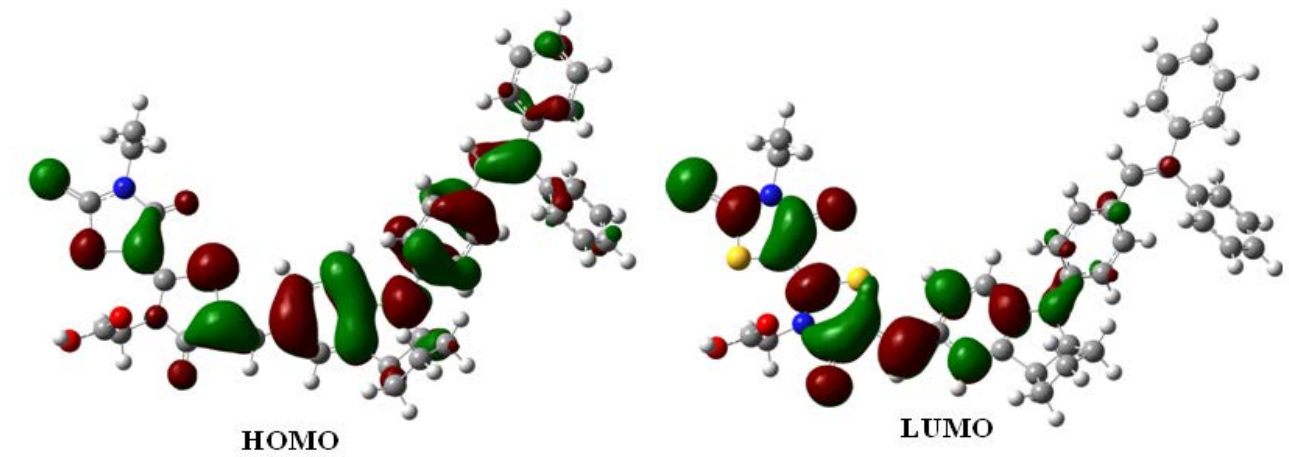

(b)

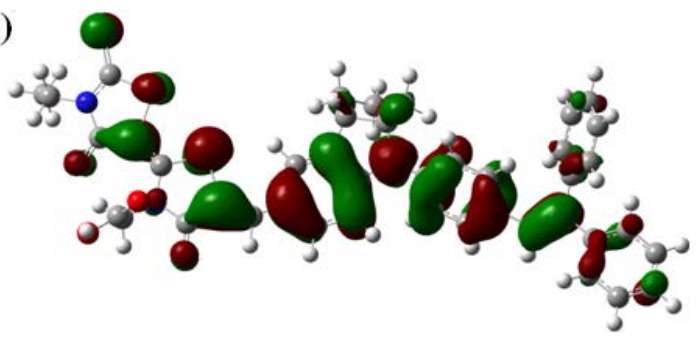

номо

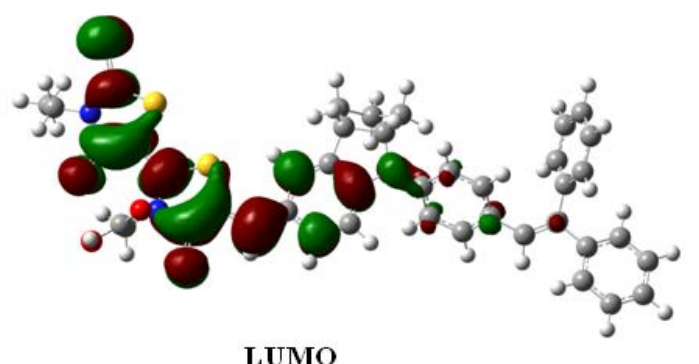

LUMO

(c)

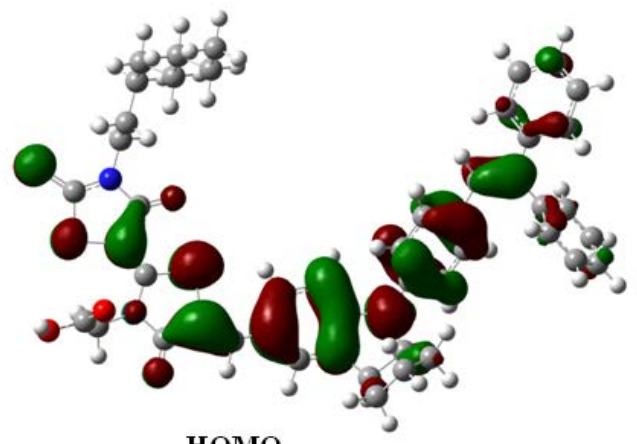

(d)
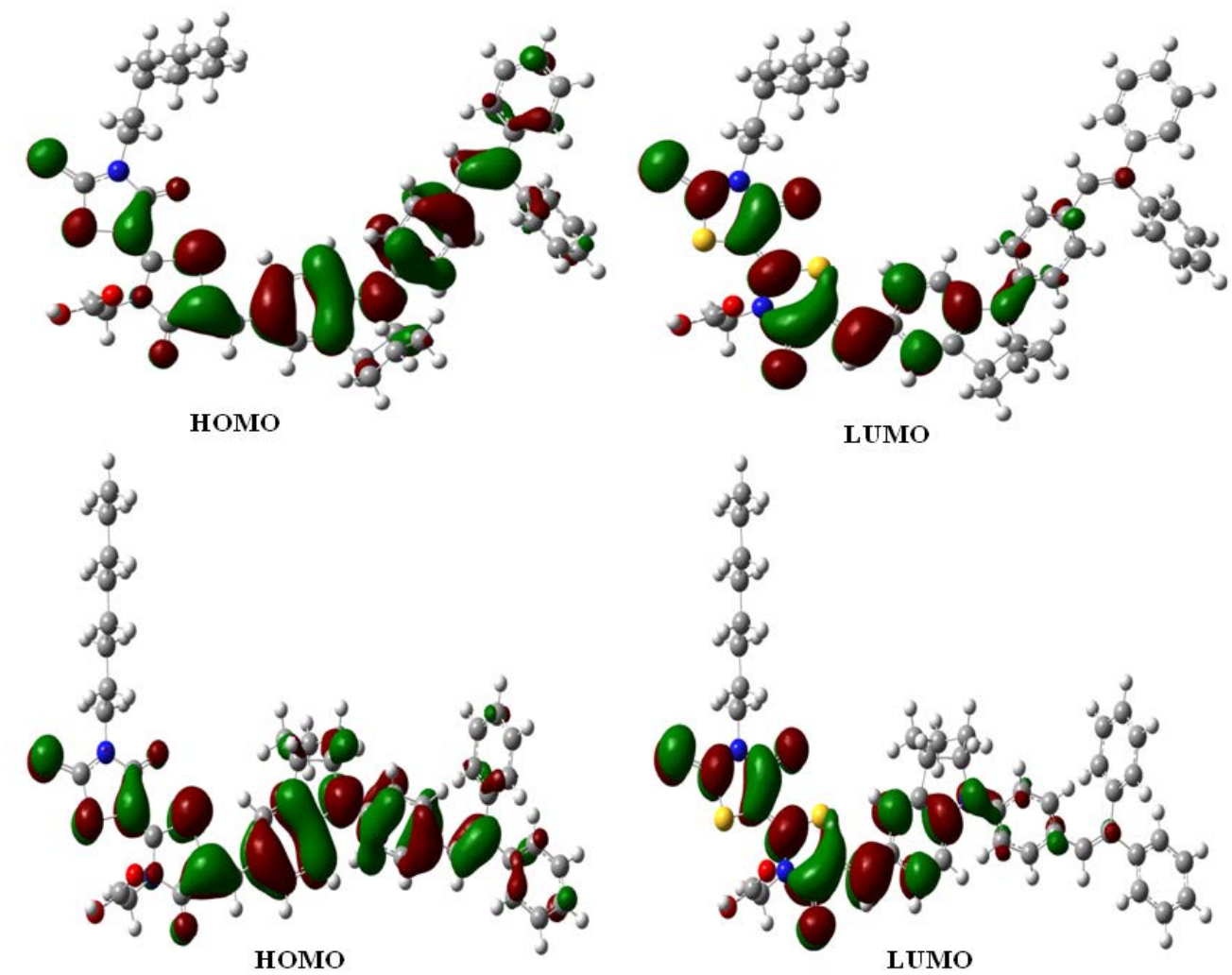

8
83
80

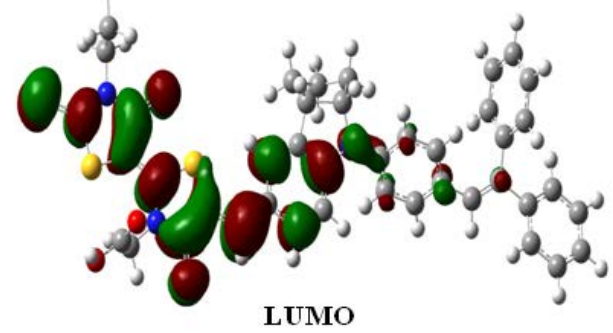

Figure 4. HOMO and LUMO orbitals of (a) D149con1 (b) D149con3 (c) D205con1 (d) D205con4. 


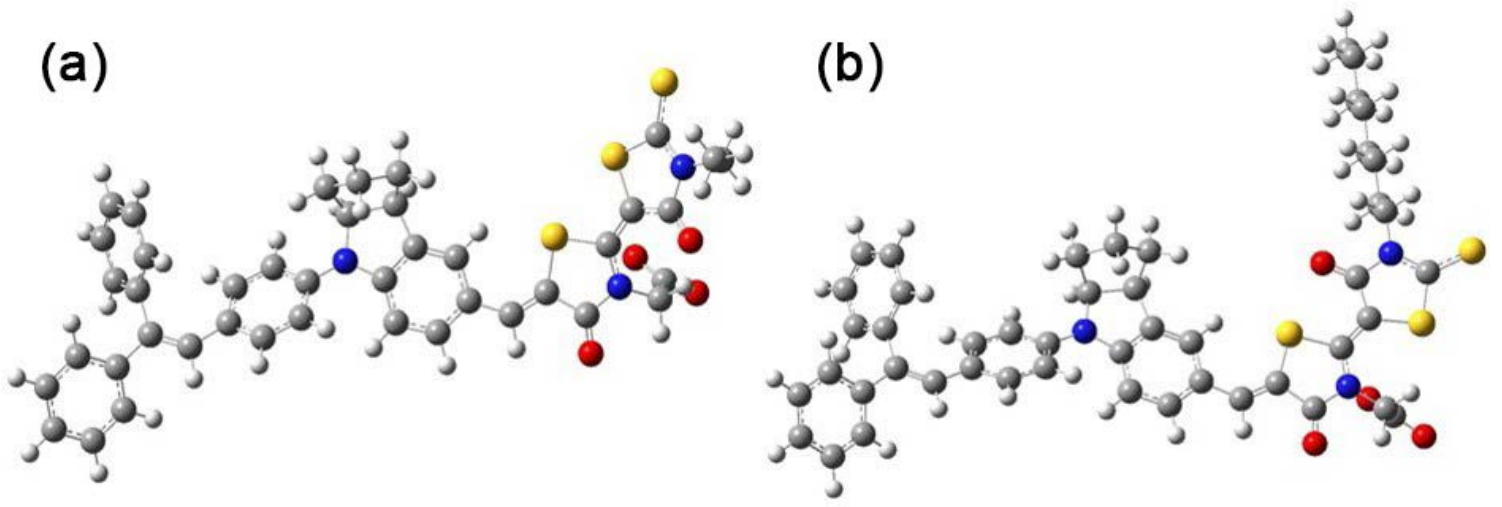

Figure 5. 3D geometries of (a) deprotonated D149con3 and (b) D205con4. The grey, white, blue, yellow and red balls represent $\mathrm{C}, \mathrm{H}, \mathrm{N}, \mathrm{S}$ and $\mathrm{O}$, respectively. 


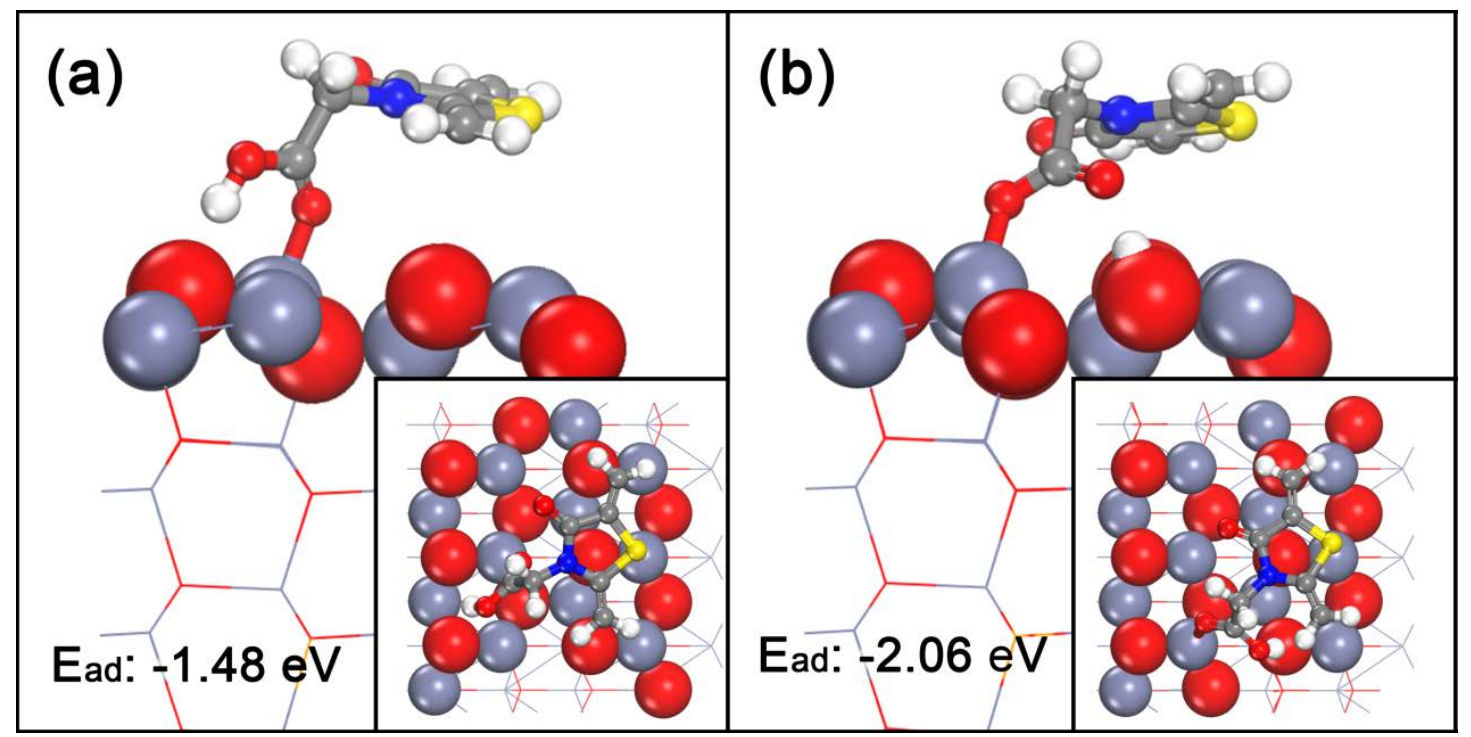

Figure 6. Illustration of two adsorption structures of a dye model that is composed of the anchoring carboxylic acid group and the attached rhodanine ring. The inserts are the top views. White, grey, red, blue, yellow and blue grey balls represent $\mathrm{H}, \mathrm{C}, \mathrm{O}, \mathrm{N}, \mathrm{S}$ and Zn atoms, respectively. The dye model is shown by stick-and-ball, the top layer of the surface is shown by CPK mode and the rest layers of the surface are shown by line representation. The adsorption energy of the dye model on $\mathrm{ZnO}$ surface was calculated in acetonitrile (relative dielectric constant $\varepsilon=36.6$ ). 


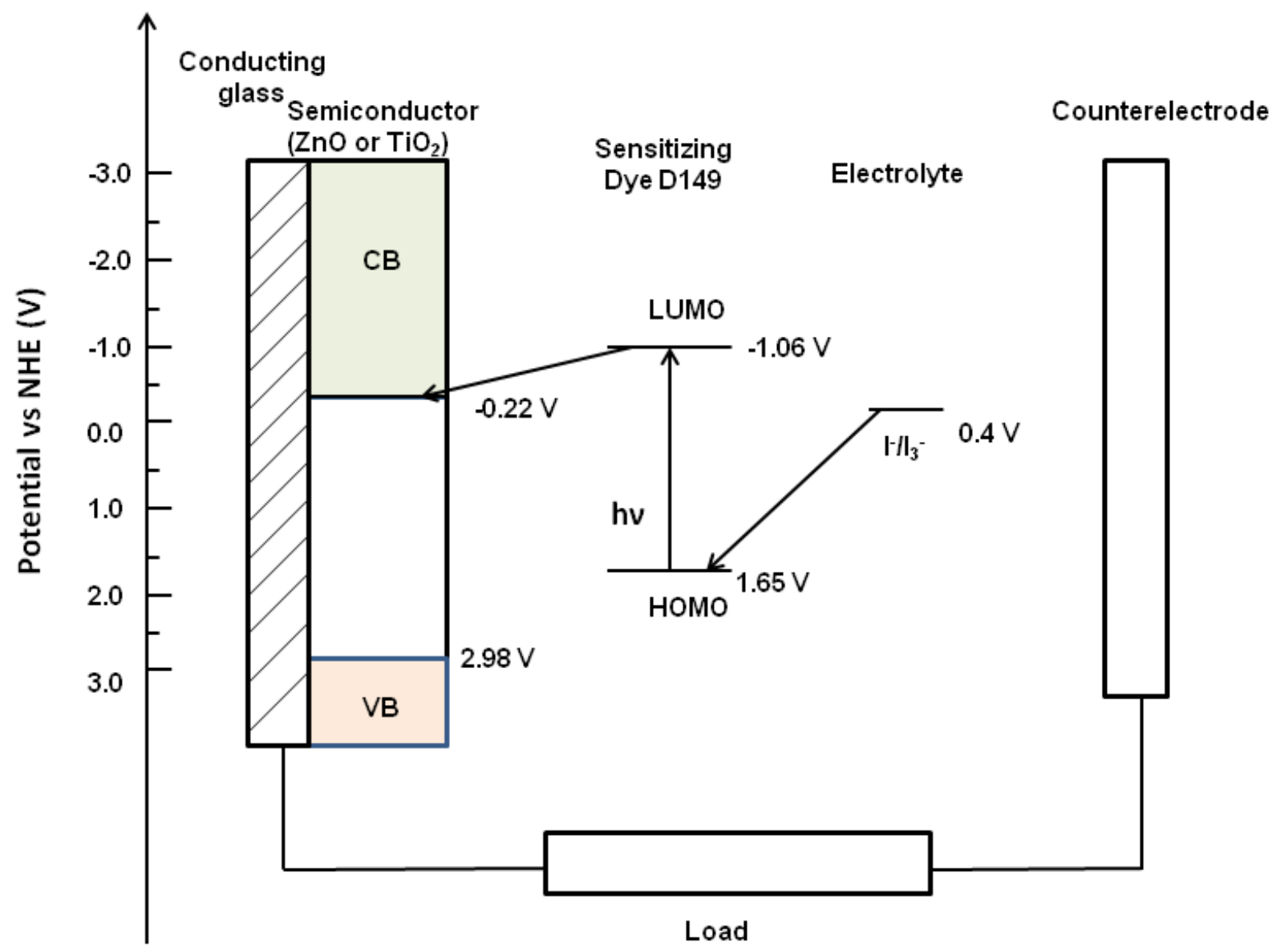

Scheme 1. Schematic energy diagram for DSSC using D149 as the sentizing dye. HOMO and LUMO energies were calculated based on the optimized geometries of $\mathrm{D}$ and $\mathrm{D}+$ using B3LYP/6-31G(d) method. $\mathrm{ZnO}$ or $\mathrm{TiO}_{2}$ is used as the semiconductor. The ionization potentials were estimated with respect to normal hydrogen electrode (NHE) potential. 


\section{Tables}

Table 1. Maximum absorbance wavelengths and relative energies of D149 and D205 by TDDFT calculations in gas phase. Three hybrid functionals B3LYP, CAM-B3LYP and MPW1K are employed.

\begin{tabular}{ccccc}
\hline \multirow{2}{*}{ molecule } & \multicolumn{3}{c}{ Absorbance / nm } & \multicolumn{2}{c}{$\begin{array}{c}\text { Relative energy } \\
\text { / eV (B3LYP) }\end{array}$} \\
\cline { 2 - 4 } & B3LYP & CAM-B3LYP & MPW1K & 0.00 \\
D149con1 & 505 & 413 & 423 & 0.14 \\
D149con2 & 539 & - & - & 0.11 \\
D149con3 & $508(505)^{*}$ & 414 & 424 & 0.05 \\
D205con1 & 505 & 414 & 423 & 0.19 \\
D205con2 & 516 & - & - & 0.03 \\
D205con3 & 504 & - & 423 & 0.00 \\
D205con4 & $504(501)^{*}$ & 414 & & \\
* The values in parentheses are results calculated using the B3LYP functional in Ref.
\end{tabular}


Table 2. Maximum absorbance wavelengths of D149con3 in five solvents by TDDFT calculations. Four different functionals (B3LYP, MPW1K, CAM-B3LYP and PBE0) are used.

\begin{tabular}{|c|c|c|c|c|c|}
\hline \multirow{2}{*}{ Solvation } & \multicolumn{4}{|c|}{ Absorbance / nm } & \multirow{2}{*}{$\begin{array}{c}\text { Exp. } \\
\text { Absorbance / } \\
\text { nm }\end{array}$} \\
\hline & B3LYP & MPW1K & CAM-B3LYP & PBE0 & \\
\hline Acetonitrile & 566 & 457 & 443 & 536 & 526 Ref. $^{55}$ \\
\hline Chloroform & 557 & 454 & 441 & 529 & 550 Ref. $^{56}$ \\
\hline Ethanol & 566 & 457 & 442 & 536 & 564 Ref. ${ }^{57}$ \\
\hline Methanol & 566 & 456 & 442 & 535 & 527 Ref. ${ }^{58}$ \\
\hline THF & $561(571)^{*}$ & 455 & $442(444)^{* *}$ & $532(535)^{* *}$ & 526 Ref. ${ }^{59}$ \\
\hline
\end{tabular}

* The values in parentheses are the DFT results in Ref. ${ }^{24}$

** These values in parentheses was calculated with $6-31+\mathrm{G}(\mathrm{d}, \mathrm{p})$ basis set in Ref. ${ }^{24}$ 
Table 3. Maximum absorbance wavelengths of D205con4 in five solvents by TDDFT calculations. Four different functionals (B3LYP, MPW1K, CAM-B3LYP and PBE0) are used.

\begin{tabular}{|c|c|c|c|c|c|}
\hline \multirow{2}{*}{ Solvation } & \multicolumn{4}{|c|}{ Absorbance / nm } & \multirow{2}{*}{$\begin{array}{c}\text { Exp. } \\
\text { Absorbance } \\
\text { nm }\end{array}$} \\
\hline & B3LYP & MPW1K & CAM-B3LYP & PBE0 & \\
\hline Acetonitrile & 557 & 453 & 440 & 529 & - \\
\hline Chloroform & 549 & 451 & 439 & 523 & 554 Ref. $^{60}$ \\
\hline Ethanol & 557 & 453 & 441 & 529 & - \\
\hline Methanol & 556 & 453 & 440 & 528 & - \\
\hline THF & $552(552)^{*}$ & 452 & $440(442)^{* *}$ & $525(527)^{* *}$ & 532 Ref. ${ }^{59}$ \\
\hline
\end{tabular}

* The values in parentheses are the DFT results in Ref. $^{24}$

** These values in parentheses was calculated with 6-31+G(d,p) basis set in Ref. $^{24}$ 
Table 4. Maximum absorbance wavelengths (nm) of deprotonated D149con3 and D205con4 in solvents by TDDFT calculations with B3LYP and PBE0 functionals.

\begin{tabular}{|c|c|c|c|c|c|c|c|}
\hline \multirow[b]{2}{*}{ Solvation } & \multicolumn{4}{|c|}{ D149con3 } & \multicolumn{3}{|c|}{ D205con4 } \\
\hline & $\begin{array}{l}\text { Absor. } \\
\text { B3LYP }\end{array}$ & $\begin{array}{l}\text { Absor. } \\
\text { PBE0 }\end{array}$ & $\begin{array}{c}\text { Calc. } \\
\text { Absorb.* }\end{array}$ & $\begin{array}{c}\text { Exp. } \\
\text { Absorb. }\end{array}$ & $\begin{array}{l}\text { Absor. } \\
\text { B3LYP }\end{array}$ & $\begin{array}{l}\text { Absor. } \\
\text { PBE0 }\end{array}$ & $\begin{array}{c}\text { Exp. } \\
\text { Absor. }\end{array}$ \\
\hline Acetonitrile & 546 & 518 & 521 & 526 Ref. $^{48}$ & 545 & 519 & - \\
\hline Chloroform & 533 & 505 & 512 & 550 Ref. $^{49}$ & 533 & 612 & 554 Ref. $^{60}$ \\
\hline Ethanol & 544 & 517 & - & 564 Ref. ${ }^{50}$ & 543 & 520 & - \\
\hline Methanol & 545 & 517 & - & 527 Ref. $^{44}$ & 544 & 519 & - \\
\hline THF & 531 & 507 & 517 & 526 Ref. ${ }^{51}$ & 532 & 564 & 532 Ref. $^{59}$ \\
\hline
\end{tabular}


Table 5. Calculated HOMO and LUMO energies of D149con3 and D205con4 using B3LYP and the $6-31 G^{*}$ basis set.

\begin{tabular}{ccccc}
\hline Molecule & LUMO/eV & HOMO/eV & Éumo- Еномо $/ \mathrm{eV}$ & $\mathrm{D}-\mathrm{D}^{+} / \mathrm{eV}$ \\
\hline D149 (con3) & -2.41 & -5.12 & 2.71 & 6.08 \\
& & & & $(1.65 \mathrm{~V})^{\mathrm{a}}$ \\
\hline D205 & -2.30 & -5.03 & 2.73 & 5.99 \\
$($ con4) & & & $(1.56 \mathrm{~V})$ \\
\hline
\end{tabular}

a: the values in brackets are the relative ionization potentials versus normal hydrogen electrode (NHE). 


\section{References}

1. Hamann, T. W.; Jensen, R. A.; Martinson, A. B. F.; Van Ryswyk, H.; Hupp, J. T. Energy Environ. Sci. 2008, 1, 66.

2. Bella, F.; Gerbaldi,C.; Barolo, C.; and Grätzel, M. Chem. Soc. Rev., 2015, 44, 3431.

3. Ye, M.; Wen, X.; Wang, M.; Iocozzia, J.; Zhang, N.; Lin, C.; Lin, Z. Mater. Today 2015, 18, 155.

4. Hardin, B. E.; Snaith, H. J.; \& McGehee, M. D. Nature Photon. 2012, 6, 162.

5. Hagfeldt, A.; Boschloo, G.; Sun, L.; Kloo, L.; \& Pettersson, H. Chem. Rev. 2010,110, 6595.

6. $\quad$ O'Regan, B.; Grätzel, M. Nature 1991, 353, 737.

7. Mathew, S.; Yella, A.; Gao, P. Humphry-Baker, R.; Curchod, B. F. E.; Ashari-Astani, N.;

Tavernelli, I. ; Rothlisberger, U.; Nazeeruddin, Md. K.; \& Grätzel, M. Nat. Chem., 2014, 6, 242.

8. Seo, J.; J. Noh, H.; Seok, S. II. . Acc. Chem. Res., 2016, 49, 562.

9. Grätzel, M. J. Photochem. Photobiol. C 2003, 4, 145.

10. Ahmad, S.; Guillen,E.; Kavan,L.; Gratzel,M.; Nazeeruddin,M. K. Energy Environ. Sci. 2013, 6, 3439.

11. Mishra, A.; Fischer, M. K. R.; Bäuerle, P. Angew. Chem. Int. Ed. 2009, 48, 2474.

12. Chaurasia, S; Lin J. T. The Chemical Record. 2016, 16, 1311.

13. Liang, M.; Chen, J. Chem. Soc. Rev., 2013,42, 3453.

14. Wang, Z. S.; Cui, Y.; Hara, K.; Dan-oh, Y.; Kasada, C.; Shinpo, A. Adv. Mater. 2007, 19, 1138.

15. Zeng, W.; Cao, Y.; Bai, Y.; Wang, Y.; Shi, Y.; Zhang, M.; Wang, F.; Pan, C.; Wang, P. Chem. Mater. 2010, 22, 1915.

16. Kitamura, T.; Ikeda, M.; Shigaki, K.; Inoue, T.; Anderson, N. A.; Ai, X.; Lian, T.;

Yanagida, S. Chem. Mater. 2004, 16, 1806.

17. Sayama, K.; Hara, K.; Mori, N.; Satsuki, M.; Suga, S.; Tsukagoshi, S.; Abe, Y.; Sugihara, H.; Arakawa, H. Chem. Comm. 2000, 1173.

18. Wang, Z.-S.; Li, F.-Y.; Huang, C.-H. J. Phys. Chem. B 2001, 105, 9210. 
19. Ito, S.; Zakeeruddin, S. M.; Humphry-Baker, R.; Liska, P.; Charvet, R.; Comte, P.;

Nazeeruddin, M. K.; Péchy, P.; Takata, M.; Miura, H.; Uchida, S.; Grätzel, M. Adv. Mater. 2006, 18, 1202.

20. Ito, S.; Miura, H.; Uchida, S.; Takata, M.; Sumioka, K.; Liska, P.; Comte, P.; Pechy, P.; Grätzel, M. Chem. Comm. 2008, 5194.

21. Nazeeruddin M.K.; De Angelis F.; Fantacci S.; Selloni A.; Viscardi G.; Liska P.; Ito S.; Takeru B.; Grätzel M. J. Am. Chem. Soc. 2005;127,16835.

22. Zhao, J.-X.; Zheng, Y.-Z.; Lu, X.-H.; Chen, J.-F.; Tao, X.; Zhou, W. ChemPhysChem. 2013, 14, 1977.

23. Martsinovich, N. ; Troisi, A. Energy Environ. Sci., 2011,4, 4473.

24. Zhang, C.-R.; Liu, L.; Zhe, J.-W.; Jin, N.-Z.; Yuan, L.-H.; Chen, Y.-H.; Wei, Z.-Q.; Wu, Y.-Z.; Liu, Z.-J.; Chen, H.-S. J. Mol. Model. 2013, 19, 1553.

25. Gaussian 09, Revision. E. 01, Frisch, M. J.; Trucks, G. W.; Schlegel, H. B.; Scuseria, G. E.; Robb, M. A.; Cheeseman, J. R.; Scalmani, G.; Barone, V.; Mennucci, B.; Petersson, G. A.; Nakatsuji, H.; Caricato, M.; Li, X.; Hratchian, H. P.; Izmaylov, A. F.; Bloino, J.; Zheng, G.; Sonnenberg, J. L.; Hada, M.; Ehara, M.; Toyota, K.; Fukuda, R.; Hasegawa, J.; Ishida, M.; Nakajima, T.; Honda, Y.; Kitao, O.; Nakai, H.; Vreven, T.; Montgomery, J. A., Jr.; Peralta, J. E.; Ogliaro, F.; Bearpark, M.; Heyd, J. J.; Brothers, E.; Kudin, K. N.; Staroverov, V. N.; Kobayashi, R.; Normand, J.; Raghavachari, K.; Rendell, A.; Burant, J. C.; Iyengar, S. S.; Tomasi, J.; Cossi, M.; Rega, N.; Millam, J. M.; Klene, M.; Knox, J. E.; Cross, J. B.; Bakken, V.; Adamo, C.; Jaramillo, J.; Gomperts, R.; Stratmann, R. E.; Yazyev, O.; Austin, A. J.; Cammi, R.; Pomelli, C.; Ochterski, J. W.; Martin, R. L.; Morokuma, K.; Zakrzewski, V. G.; Voth, G. A.; Salvador, P.; Dannenberg, J. J.; Dapprich, S.; Daniels, A. D.; Farkas, Ö.; Foresman, J. B.; Ortiz, J. V.; Cioslowski, J.; Fox, D. J. Gaussian, Inc., Wallingford CT, 2009.

26. Becke, A. D. J. Chem. Phys. 1993, 98, 5648.

27. Lee, C.; Yang, W.; Parr, R. G. Phys. Rev. B 1988, 37, 785.

28. Lynch, B. J.; Fast, P. L.; Harris, M.; Truhlar, D. G. J. Phys. Chem. A 2000, 104, 4811.

29. Yanai, T.; Tew, D. P.; Handy, N. C. Chem. Phys. Lett. 2004, 393, 51.

30. Adamo, C.; Barone, V. J. Chem. Phys. 1999, 110, 6158.

31. Runge, E.; Gross, E. K. U. Phys. Rev, Lett, 1984, 52, 997. 
32. Cossi, M.; Barone, V. J. Chem. Phys. 2001, 115, 4708.

33. Cossi, M.; Rega, N.; Scalmani, G.; Barone, V. J. Comput. Chem. 2003, 24, 669.

34. GaussView, Version 5, Dennington, Roy; Keith, Todd; Millam, John. Semichem Inc., Shawnee Mission, KS, 2009.

35. Kresse, G.; Furthmüller, J. Computational Materials Science 1996, 6, 15.

36. Kresse, G.; Hafner, J. Phys. Rev. B 1994, 49, 14251.

37. Perdew, J. P.; Burke, K.; Ernzerhof, M. Phys. Rev, Lett, 1996, 77, 3865.

38. Kresse, G.; Joubert, D. Phys. Rev. B 1999, 59, 1758.

39. Blöchl, P. E.; Jepsen, O.; Andersen, O. K. Phys. Rev. B 1994, 49, 16223.

40. Pastore, M.; Mosconi, E.; De Angelis, F.; Grätzel, M. J. Phys. Chem. C 2010, 114, 7205.

41. Oum, K.; Lohse, P. W.; Flender, O.; Klein, J. R.; Scholz, M.; Lenzer, T.; Du, J.; Oekermann, T. Phys. Chem. Chem. Phys. 2012, 14, 15429.

42. Fakis, M.; Hrobárik, P.; Stathatos, E.; Giannetas, V.; Persephonis, P. Dyes Pigments 2013, 96, 304.

43. Waite, T. In Mineralogical Society of America Reviews in Mineralogy, 1990, 23, 559.

44. Zaban, A.; Ferrere, S.; and Gregg, B.A. J. Phys. Chem. B, 1998, 102, 452.

45. Xu, Y.; Schoonen, M. A.A. Am. Mineral., 2000, 85, 543.

46. Seager,C.H.; Myers, S.M. J. Appl. Phys. 2003, 94, 2888.

47. $\quad \mathrm{Xu}, \mathrm{F} . ;$

48. Azpiroz, J. M.; De Angelis, F. J. Phys. Chem. A 2014, 118, 5885.

49. Beltrán, A.; Andrés, J.; Calatayud, M.; Martins, J. B. L. Chem. Phys. Lett. 2001, 338, 224.

50. Ozawa, K.; Suzuki, M.; Tochikubo, R.; Kato, H.; Sugizaki, Y.; Edamoto, K.; Mase, K. J. Phys. Chem. C 2016, 120, 8653.

51. Mathew, K.; Sundararaman, R.; Letchworth-Weaver, K.; Arias, T. A.; Hennig, R. G. J. Chem. Phys. 2014, 140, 084106.

52. Mathew, K.; Hennig, R. G. VASPsol - Solvation model for the plane wave DFT code VASP, https://github.com/ henniggroup/VASPsol .2015.

53. Mathew, K.; Hennig, R. G. arXiv:1601.03346 2016.

54. Hagfeldt, A.; Boschloo, G.; Sun, L.; Kloo, L.; Pettersson, H. Chem. Rev. 2010, 110, 6595. 
55. Chiu, W.-H.; Lee, C.-H.; Cheng, H.-M.; Lin, H.-F.; Liao, S.-C.; Wu, J.-M.; Hsieh, W.-F. Energy Environ. Sci. 2009, 2, 694.

56. Dentani, T.; Kubota, Y.; Funabiki, K.; Jin, J.; Yoshida, T.; Minoura, H.; Miura, H.; Matsui, M. New J. Chem. 2009, 33, 93.

57. Lohse, P. W.; Kuhnt, J.; Druzhinin, S. I.; Scholz, M.; Ekimova, M.; Oekermann, T.; Lenzer, T.; Oum, K. Phys. Chem. Chem. Phys. 2011, 13, 19632.

58. Le Bahers, T.; Pauporte, T.; Scalmani, G.; Adamo, C.; Ciofini, I. Phys. Chem. Chem. Phys. 2009, 11, 11276.

59. Kuang, D.; Uchida, S.; Humphry-Baker, R.; Zakeeruddin, S. M.; Grätzel, M. Angew. Chem. Int. Ed. 2008, 47, 1923.

60. Higashijima, S.; Miura, H.; Fujita, T.; Kubota, Y.; Funabiki, K.; Yoshida, T.; Matsui, M. Tetrahedron 2011, 67, 6289. 